\title{
Business Travellers' Connections to Home: ICTs supporting Work-life Balance
}

\author{
Published in New Technology, Work and Employment \\ Professor Adele Ladkin (Bournemouth University) \\ Dr. Cheryl Willis (Bournemouth University) \\ Dr. Juliet Jain (UWE) \\ Dr. William Clayton (UWE) \\ Dr. Marina Marounda (University of Sussex)
}

\begin{abstract}
This paper examines the role of information communication technology in enabling connections to home for work related travellers. Although digital connectivity for work related tasks are well researched, the use of digital technology for home communication is under-researched. The study draws on a qualitative study of UK-based organisations and business travellers to explore how these travellers use ICTs for personal use whilst 'on-the-move'. The findings reveal that organisations are supportive of work-life balance for employees, but fail to consider specific needs of those whose work takes them away from home. For business travellers, insights are gained into practices around connecting to home and the value of this virtual presence for relationships with family whilst absent and work-life balance. The study identifies and discusses practice occurring around three activities; checking in, maintaining relationships with home and sharing experiences.
\end{abstract}

\section{Introduction}

Our paper explores the role that ICTs play in enabling connections to home for people whose work necessitates some element of mobility. Work-related travel has become commonplace and is an integral aspect of a wide range of employment contexts (Gustafson, 2012). Some occupations are inherently mobile, where travel is an integral part of the role such as transport crew and military personnel. Others may involve frequent and or ad hoc travel as in the case of travelling for meetings. Common to all engaged in work related travel, is absence from home for periods of time. ICTs are reshaping the experience of work related travel and absence for both travellers and their family who remain at home. Employers have responded to the opportunities and challenges of increased mobility in their workforce by enabling travellers to be in possession of the latest technology to facilitate connectivity, enabling 'access anytime, anywhere' (Perry et al., 2001; Koroma, et al., 2014). Much of this rhetoric focuses on connecting for work, with both the positives and negatives of ICT enabled mobility and flexibility for work 
widely recognised (Numes, 2005; Kaufman-Scarborough, 2006; Hilbrecht et al., 2013). However, the needs for connectivity may not only be concerned with work related connections but also for enabling a sense of work-life balance whilst on the move. An important but neglected aspect in ICT driven mobility is concerned with how those who travel for work connect to home and how being 'virtually present' for loved ones and significant others might foster a sense of work-life balance. Such connections may be important in avoiding the risk of stress and burnout associated with work related travel and the inevitable disruptions it causes to family life; leading to 'work-family conflict' (Jensen, 2014; Makelä et al., 2014). Our paper argues that the use of ICTs for those who travel for work is only partially understood, with limited understanding of its role in connecting to home and enabling a sense of work-life balance. From an organisations perspective, technology is primarily a means to facilitate work. For the work related traveller who faces a particular set of work-life challenges, technology for them may be as much about fostering meaningful remote engagement with home as it is about enabling work to be carried out.

ICTs have become important for maintaining relationships with people who are physically distant either synchronously as in the case of instant messaging and phone calls (Greene et al., 2010; Tang, 2012) or asynchronously by message boards and emails (Wacjman et al., 2008). Such communications may be important for the psychological well-being of those who are absent from home and family and this is emerging as an important line of research enquiry (White and White, 2007, Neuhofer et al., 2013). Our paper places ICTs at the centre of the discussion on connecting to home. We acknowledge the well-established and theoretically diverse body of work that explores how ICTs have altered working practices and relationships to home (Nansen et al, 2010) and in particular the implications on work-life balance for the 'always on' culture which can be positive as well as negative. We also acknowledge the body of work that explores how technology is used to maintain relationships at a distance, for example in the case of maintaining family practice and connections to home (McDowell, 2007; Morgan, 2011) and in remote of mobile parenting (Madianou and Miller, 2011).

Our contribution is an exploration of the practice of using ICTs to enable connections to home in the context of working 'away', and how they might be used to foster a sense of work-life balance for those on the move. We focus on practice as it has the potential to explore the role of technology in social relations (Horst, 2013) and is useful for illustrating the use of digital technologies in everyday life (Pink et al, 2016). We explore technology intended primarily for work activities used in a non-work role, offering empirical evidence from a group of UK based business travellers and organisations that have a partially mobile workforce. There is an established body of work indicating those who travel for work have a particular set of challenges 
affecting their health, wellbeing and work-life balance. If we accept the assertions that mobile working is becoming the norm, understanding how ICT can be used positively to facilitate and maintain relationships with family and home may indicate one way forward for improved wellbeing and work-life balance for those on the move and their families. Our work aims to explore three questions; how do organisations understand work-life balance in the context of a mobile workforce, what are the practices for ICT use in connecting to home, and how might we facilitate these work/home relationships for improved work-life balance? Our work aims to enrich the studies of business travel through focusing on this neglected area, and its relevance to work-life balance. We locate our work broadly within boundary theory. In our business travel context, ICTs remove spatial boundaries, enabling virtual presence, thus extending the opportunity for family interaction. It is argued elsewhere that improving or extending the work life interface has links to wellbeing (Bergström Casinowsky, 2013), and ICTs have the capacity to reconfigure this interface. Through our focus on practice, we also aim to contribute to deliberations on what constitutes the essence of work-life balance (Jones et al, 2006). Examining the ways ICTs are used for connecting to home while on the move may reveal what is considered important in work and family relationships.

\section{Background and Context}

The business travel sector and ICTS

Globally, 14\% of all international tourist arrivals reported travelling for business and professional purposes (UNWTO, 2015). Figures for the UK show that business visits grew from 7.9 million visits in 2013 to 8.3 million in 2014, with spend by business travellers in 2014 at $£ 5$ billion (ONS Travel Trends, 2015). Despite the limitations of obtaining definitive figures for this sector, estimates and predictions agree that the amount of international travel primarily motivated by work is increasing (Haynes, 2010). Business travel encompasses a range of related occasions such as conventions, conferences, trade shows, exhibitions, incentive events as well as business meetings (UNWTO, 2014).

Within the business travel literature, there has been some focus on the development of typologies and categories of business mobility (e.g. Jones, 2013; Aguilera and Proulhac, 2015). Gender differences are also considered with business travel generally being more common amongst male professionals over females (Gustafson, 2006, Aguilera, 2008). The consequences of business travel are also gendered, with the mobility of women being affected by their tendency to shoulder more responsibility for caring roles resulting in restricted career 
opportunities (Black and Jamison, 2007). Evident also is that when women are the main travellers in the family unit, they may still have the majority of domestic responsibilities (Bergström Casonowsky, 2013).

In the context of new technology and working practices, there is continued debate in the travel literature concerning the use of ICTs and whether they could or should diminish the size of the business travel sector through enabling virtual connectivity and eroding the 'compulsion to physical proximity' which has characterised the industry to date (Storme et al., 2013, p12). The growing internationalisation of many organisations has driven this increased need for business travel, as face-to-face communication is often required for knowledge-intensive work processes (Jones, 2013). Such contact is also arguably a pre-requisite to building trust between actors and is also an expression of commitment (Aguilera, 2008; Faulconbridge et al., 2009; Gustafson, 2012). This desire for co-presence together with the geographical spread of connections brought about by new technologies seems therefore, to have given rise to a steadily increasing amount of business travel (Bergström Casinowsky, 2010). This has been discussed in terms of physical travel and ICTs as being 'mobility allies' rather than being communication substitutes (Haynes, 2010). Evidence appears to point to an unlikely chance of reductions in business travel despite further ICT advances (Aguilera, 2008; Larsen et al., 2008; Haynes, 2010; Aguilera and Proulhac, 2015). Discussion around business travellers and work-life balance therefore remain important.

\section{Work-life balance and the business traveller}

The concept of work-life balance has been employed to interrogate and explain the ways in which individuals negotiate the time they spend at work and at home. This has been interpreted by researchers as an appropriate division of time and attention between work and other areas of life (Hilbrecht et al., 2013). Work-life balance is a subject of much debate, with a well-developed theoretical base. One useful way to conceptualise the relationship between work life and home life is through the notion of boundaries or borders. Spheres of work and home life can be considered as different territories which have more or less rigidly defined borders, borders which workers must cross on a regular basis. Boundary theory is often used as a way to understand the work-life interface (Sayah, 2013; Yeow, 2014). Border theory concerns the boundaries that divide place, people, and time associated with work versus family roles (Campbell Clark, 2000). A comprehensive review of boundary theory and border theory is beyond the scope of this paper, but is provided by Allen et al (2014). They suggest that both theories provide frameworks intended to increase an understanding of the ways in which individuals create and manage the boundaries between work and family. There is wide recognition of the increasing 
difficulty of maintaining work and home boundaries with the ever-increasing use of ICTs in everyday life (Gold and Mustafa, 2013), as digital technologies allow for increased blurring of the space between work and home. How individuals transition between work and family life through technology in an effort to achieve work-life balance is the central theme of this paper, through which we contribute to debates on ICT enabled border crossing and its relationship to work-life balance in the context of business travel.

Numerous studies suggest that a healthy work/life balance is most often a cornerstone of good personal relationships, health, and mental wellbeing (e.g. Fleetwood, 2007; Dewe and Kompier, 2008; Peters et al., 2009; James, 2011). Despite the complexity of the intersection between work and family (Hilbrecht et al., (2013), time spent with family is an important aspect of worklife balance discussions (Carlson et al., 2009). However, negotiating presence and time in the competing spheres of work and home can be problematic. In discourses of work-life balance, the negative impacts of periods of absence from family life are a prevalent theme. Also important are discussions around policy development around issues such as flexible working practices and family-friendly hours, with greater emphasis on work-family balance (Carlson et al., 2009). Flexible work designs are an important aspect of this (Ter Hoeven and Zoonen, 2015). Such policies are promoted as beneficial for both individuals and organisations, who benefit from less stressed employees who it is argued, are then more productive (Espino et al., 2002). These discussions often have practical elements that have emphasised working practices to enable parents (and particularly mothers) the flexibility to work and continue with childcare responsibilities (Small et al., 2011). Others contest that work-life balance is an issue for all, not just those with caring responsibilities (Jamieson and Morton, 2005). Evidence suggests that employers who invest in strategies promoting work-life balance are most likely to attract quality candidates and have higher retention rates (Casper and Buffardi, 2004; Beauregard and Henry, 2009).

The relationship between business travel studies and work-life balance debates is that those who travel in the course of work have particular sets of challenges with regards to work-life balance. Early studies were concerned with the health implications of business related travel (e.g. Rogers and Reilly, 2002) including the diets and fitness levels of business travellers (Lee and McCool, 2006; Tompkins, 2008). Subsequent studies have shifted attention to exploring the psychological, emotional and behavioural implications of business travel and recognition that business travel has an impact not only on the traveller but also on the family and support structure left at home (Makela et al., 2014; Jensen, 2014; Gustafson, 2014). Business travel can also involve stress, anxiety and frustration, associated with increased workloads, sleep problems, burnout and difficulties in balancing work and private life (Gustafson, 2014; Jensen, 
2014; Makela et al., 2014; Westman and Etzion, 2002). DeFrank, (2000) observes that business travel and the stress it may create can cause emotional upset, physical illness, decreased performance and problems achieving company objectives. These difficulties have consequences both for the organisation as well as for the individual. McDowell and Nicolas (2012) discuss how business travel is different when compared to commuter relationships and occupations that demand long periods of absence, as it is irregular in nature and thus has unique challenges and benefits. The nature of irregular business travel means that there may not be a clear dividing line between 'work-time', which is owned by the employer and 'leisure time', which is owned by the individuals (Holley et al., 2008). Overlaps between work and home can cause conflicts and even serious impacts, with stress, marital problems and behavioural problems for children among reported symptoms (Gustafson, 2006). Evidence through the literature appears to suggest that the potential for behavioural, job performance and family/work life problems of business travellers is rarely considered to be a significant human resource management factor (Ivancevich et al, 2003) and that 'companies 'do not seem to account for the fact that employees often see business travel in a 'negative light' (Aguilera, 2008, p1114).

This is not to suggest that travel for work purposes is wholly negative, as it can have positive outcomes. It can be perceived as stimulating and enriching, and a source of variation and new experiences. It may also evoke a sense of freedom and independence and may be an important part of workers' identities and lifestyles (DeFrank, 2000; Larsen et al., 2006; Gustafson, 2012). Work by Westman, Etzion and Gattenio (2008) and Weston, Etzion and Chen (2009) offer interesting insights into how the business trip offers a form of "respite" from the normal workplace, home and family. The use of ICTs can however, challenge this respite due to the possibility of remaining connected to the workplace, home and family. .

Despite the positive benefits of business travel for individuals, organisations and more generally to global economic development, the 'business travel curse' (Beaverstock et al., 2009) takes its toll on the traveller. Ivancevich et al., (2003) note that the potential for behavioural, job performance and family/work life problems of business travellers is rarely considered to be a significant human resource management factor. For employers to focus only on the economics of business travel, whilst ignoring the work-life balance issues of the traveller is 'short-sighted, incomplete and insensitive' (Ivanevich et al., 2003, p141). How ICTs might be used to foster a sense of work-life balance for those on the move is therefore a consideration of our paper.

\section{Methodology}


Our paper draws on research undertaken for a two year multi-disciplinary study funded by the Engineering and Physical Sciences Research Council (EPSRC) exploring the evolving nature of family life within the digital age to support work-life balance for mobile workers (Name of project removed for reviewing purposes). The aim of this study was to understand the domestic rituals that families share, and how existing technologies are used by people travelling away from home in the course of work to connect with 'home life' and the facilitation of work-life balance. The research combined qualitative social science approaches with design-oriented research as an overall creative orientation to qualitative research. The first stage of the research conducted interviews with organisations that have a partially mobile workforce, the second stage involved interviews with employees who travel for work and their families, and the final stage was indepth design ethnologies with five families, resulting in the deployment of technological prototypes designed to connect absent workers with home. In this paper, the empirical evidence is drawn from stages one and two.

A note with regard to the sample is required. The project was concerned with mobile workers, who represent a broader group than business travellers. Business travel is widely understood to be 'work-related travel to an irregular place of work, for example, to visit a client, participate in a conference or attend a meeting' (Aguilera, 2008, p1109). This represents a 'type' of business traveller, distinct from 'travelling workers' whose occupation per se necessitates travel (Kellerman, 2010). As a result, the respondents whose occupation did not fit within the business travel category were removed.

\section{Employer interviews}

Organisations were identified from sector-based information that indicated they might have at least a partially mobile workforce. In this exploratory work, there were no pre-set criteria as to which organisations to select. Within the organisations, participants were human resource personnel as they have the broad understanding and overview of workforce organisational policies and practices. Fifteen interviews were conducted representing various industry sectors and sizes of enterprise, from large multi-national conglomerates to small and medium sized enterprises that operate across the UK. Sectors included tourism and hospitality (hotels, tour operators, cruise lines), transport (airlines), logistics/haulage, media (TV channel), consultancies, education and NGOs / ex-QUANGOs (see table 1 for breakdown of organisation types). Research questions included those around the company structure and composition, mobility patterns of workers, reasons for travelling for work, the use of ICTs and issues around work-life balance and how employees are supported to achieve this balance. There were location constraints associated with the available funding, with the majority employers being 
based in London and the South East. This also influenced our sample size due to resource and time constraints.

\section{Insert Table 1 about here}

Semi-structured interviews took place at the organisations premises during a six-month period beginning in July 2013. Questions were guided by themes identified from work-life balance literature related to organisational practices and included $X, Y$ and $Z$. Interviewees were also given freedom to expand upon responses as they wished. Interviews typically lasted around 45 minutes and were recorded and later transcribed. Interpretive thematic analysis techniques were used to develop an initial coding of the data, with the following themes emerging; patterns of mobility, organisational attitudes and policies towards business travel, support for mobile workers, technology and the use of ICTs and work-life balance. These were later refined by a more focused coding process (Charmaz, 2006). This process provided the 'effective scaffolding' (Jennings et al, 2010) required to analyse and interpret the data. NVivo (version 10) software was used in the process.

\section{Employee interviews}

Participants were recruited through targeting employers who we felt may have at least a partially mobile workforce. Advertisements for participants were also placed on social network sites such as Linked-in and Mumsnet, and through press releases, and word-of-mouth contacts. We undertook this range of participant recruitment strategies in order to try and capture a range of types of worker, and also to expedite recruitment. Nine of our participants were recruited from employers, six were personal contacts, four came from the social media sites and two from our press release. For our research, we were interested in people who had to travel away from home overnight or longer as part of their job with a frequency of six or more trips per year, or fewer but with a significant duration. These parameters were decided to enable a variety of workers who travel in the course of work to participate, rather than just those who might be classified as "professional workers'. However, recruitment from outside this professional category proved to be unsuccessful, resulting in our sample comprising of lawyers, consultants, journalists and project managers, thus fitting with the business traveller definition. The general profile of the mobile workers is shown in table 1 above. The occupations of our participants are skewed by those who were willing to take part. However as travelling away for work was the criteria and not occupation type, this was not a major concern. Where possible, family members of the mobile workers took part in a follow up interview. Of our twenty-one participants, twelve agreed to a follow up interview with their families. Nineteen workers and twelve family interviews 
are included in this discussion (removing the two airline workers who fall outside the business traveller definition. Neither had a follow up family interview).

The interviews with employees were semi-structured and focussed on work roles, frequency and rationale for work-related travel, what they enjoyed and disliked about travelling and how this related to family life. The ways in which family shaped the experience of absence was explored as well as how digital technology was used for communicating with family members and issues around work-life balance. For the purposes of this research, the definition of 'family' was broad and the only stipulation given was that the participant must be living with at least one other person (e.g. partner, spouse, child, parent, etc.). Where family members were included in the research, the employee interview was followed up by a second interview, which then included the selected family member(s), which could include children.

Interviews took place in the participants' home and they lasted for approximately ninety minutes. Interviews were again recorded, transcribed as described earlier. Nodes were created initially based around the themes identified as important which formed the structure of the interviews (e.g. communication, family activities and use of technology). Subsequent nodes emerged from the data and were examined in the context of wider themes; 'being away' for example, raised a number of interesting related issues including 'family activities at a distance' and 'managing absence'.

\section{Findings and Discussion}

The findings presented in this paper are drawn from interviews with organisations and interviews with business travellers and their families. In relation to organisations, we sought to understand how organisations understand work-life balance in the context of a mobile workforce and how ICTs are used to support mobile workers. For employees and their families we sought to explore the practices for ICT use in connecting to home. The findings are presented by summarising the themes which were discussed most frequently through the interviews. Although the interview sample is small and is not intended to be representative of all business travellers, this discussion and supporting quotes are indicative of the general narrative which emerged from the interviews,

Organisational perspectives 
We began by asking our organisations about their attitudes towards work-life balance. All of the organisations considered work-life balance a priority for their employees and had policies that aimed to foster a positive work-life balance.

"Embedded into our culture is that we encourage work-life balance" (employer: hotel)

In common with organisational practice, the focus in relation to work-life balance was on policies around flexible working practices and family-friendly hours. Flexible working hours ( $p / t$, leave, working from home) is offered as part of support for work-life balance.

"We are a family friendly organisation, people are taken care of" (employer: airline)

In terms of work life balance practices, organisations reported they respond to and accommodated employees' requests where possible. When addressing work-life balance issues, individual and family circumstances were taken into account, as well as years of service with company (loyalty), prior shifts and/or leave or holiday taken. For the most part, although important exceptions were noted, the employers' approach is mainly articulated with reference to having/or not having children and thus by implication the emphasis is largely placed on 'traditional' family structures. Some interviewees pointed to mobile ways of living and working as more suited to people of certain age and family status (i.e. young, single, few home responsibilities). All organisations were explicit in the need for travel as part of the hiring process where relevant. There was also genuine willingness to be flexible and accommodating by all organisations, either informally or through direct formal requests for work-life balance support. Such requests are however, open to all employees and none of our employers identified a need for separate policies for their business travellers with regards to work-life balance.

Turning to discussions around employees who travel as part of their work, we asked our organisations to define their mobile workforce and comment on the use of ICTs for connecting to home. The ways in which workers who travel were defined was diverse across the sample, which is not surprising given the different nature of the organisations. However what became clear was that in organisations where travel was not a core part of the business, employees travelling for work purposes tended to be senior staff members with managerial responsibilities, fitting with notions of the contemporary business traveller. In contrast, in businesses where travel was a core component (for example road haulage, air transport and cruises), workers at all levels were engaged in travel. 
Senior managers, who are the core business travellers, were generally issued with technology to enable communication with the workplace (smart phones, tablets, or laptops). Keeping in touch with the employee and ensuring they were able to do their job effectively whilst away was understandably prioritised by all employers interviewed and all considered that devices were primarily for work connections. Indeed a minority of employers stated that devices were to be used 'for business purposes only' (employer: media). However, some flexibility was allowed by most employers in that they allowed employees to use devices for personal use to communicate with family whilst away, with stipulations given that this should be 'within reason' (employer: hotel). For others, expenses and/or subsidised telephone cards were provided which were considered to cover the costs of any personal communications. A very small number of employers however, did assume that employees would use their own personal devices and connect via internet cafés and other public Wi-Fi areas as the following quote demonstrates;

'Technology isn't as much of a barrier as it used to be. They will probably get internet connectivity at some point in the day. Even in those sort of very poor countries, they are still full of cyber cafés so there are ways to make contact' (employer: international charity).

Whilst technology was not explicitly recognised by most employers as integral to work-life balance, the majority of employers did consider that being able to communicate with home and family was important for employee well-being, with one employer commenting;

"One of the ways of keeping staff happy is to provide as many opportunities to interact with family as possible" (employer: hotel),

Our findings identified that management within organisations consider and value the work-life balance of their employees, although no-one identified different or specific work-life balance needs for those who travel away from home for work. Priorities for ICTs use were around the importance and use of technologies for work purposes rather than for enabling workers to connect to home. We conclude therefore that organisational work-life balance policies are not currently mindful of specific needs of travelling workers, and the potential for work-life balance policies that underpin and employees' use of ICT when travelling is not yet realised. For organisations, the use of ICTs for border crossing is confined to bridging locations within a work role rather than for border permutation between work and family roles. 
To facilitate our discussions with employees, we first asked them to comment on the devices they carry and their experiences with technology. Our discussions revealed that using ICTs to connect to home was an important issue for those who travel for work and also for their families, largely so they could take part to some extent in family life. The main devices used to make contact with home were smartphones, laptop computers and tablets. These enabled different forms of communication, from phone calls, text messages, skype (video calling), facetime (video calling), emails, facebook and snapchat (image sharing).

All employees were equipped by their employer with devices which enabled them to work onthe-move. Connections speeds and Wi-Fi availability were however, problematic for some. One participant noted 'most hotels have got Wi-Fi' although he did go on to comment that the connections are usually slow and designed for people to download emails rather than for "people to start streaming videos or making voice over IP calls" (male, technical adviser).

All participants agreed that the use of ICTs were necessary for work on-the-move. However, some raised the issue of blurring of boundaries between work and non-work time, in particular working longer hours when travelling, facilitated by technologies which allows you to "go back to the hotel, have a club sandwich and work till midnight" (male, technical adviser).

Working whilst on the move also crosses into non-work time as travelling can occur early mornings and late evenings and whilst all participants who travelled by train agreed that this was a good use of time; "I choose to get the train and I can actually work on the train so it's quite useful" (male, consultant), the blurring of boundaries is evident.

When not working on-the-move, technology was also considered positively in facilitating working from home which did allow for some flexibility in working conditions as the following quote demonstrates;

"Sometimes I work from home if I need to be at home for a specific reason. I can just sit down and concentrate on work and I can link into the company computer systems using a special key fob" (female, consultant).

These discussions confirm the established debates surrounding the use of ICTs and its implications for work-life balance. We then explored practice around connecting to home. This was a significant part of ICT use for all participants, with practice surrounding the facilitation of three activities; checking in, maintaining relationships and sharing experiences. 
Checking in was the most frequently discussed function of communication, in essence making contact with families to let them know of safe arrival and for a brief catch up. These types of communication were reassuring for both the travellers and their families at home as the following quote demonstrates:

'I think he likes to be reassured that, you know, I'm in one piece. It's literally checking in' (female, NGO worker).

Checking in was usually performed either through a phone call or via text message, depending on the context and time difference, and normally involved only the traveller and their partner. Practice surrounding checking in was not about quality communication, but reassurance, valuable to both employees' and their families.

Maintaining relationships on the other hand involved more lengthy communications, revolving around what had happened during the day. This could include the whole family for example;

"I like to hear what (partner) been up to and how her day has gone. There's that sort of emotional connection that it's nice to maintain and the sort of, support element of a partnership where you can listen and encourage and be a sort of sounding board or feedback for the other person" (male, consultant).

These sorts of communication were also a way of bringing the family together and spending time with children. In these instances, having a conference function on a mobile technology was described as creating a feeling of togetherness such as in the following quote:

"I really like the fact that we're able to chat on speakerphone whether it's in the car and have all four of us able to talk, to me, that's really important. I feel like we've all just come back and touched base, even though, you know, one of us is away" (female partner of male consultant).

Mobile technology in this way allows spatial flexibility, and provides an opportunity for immediacy and intimacy in routines connected to home.

Sharing experiences was a vital practice shared by all our participants. Those travelling away from home were keen to share experiences of their travels with their families. This is an important aspect of more recent digital technology in that it enables expressive forms of virtual 
communication through features such as video calling and digital picture sharing, creating visual experiences of travel for participants. For all our participants, this provided a source of comfort for both the 'absent' worker through connection to home and also for families at home who could also enjoy some kind of reciprocal experience of being with the traveller, as the following quote demonstrates;

"I always show (partner) my hotel room and it just feels like I'm not alone. Somehow that always makes me feel better" (female consultant).

By providing a visual aspect to the communication, families could be brought more fully into the mobile worker's experience:

"[Mobile worker] will - say for example he was in Paris - she'd [daughter had] been learning about Paris so he sent a message, (...) and said show our eldest daughter this, it's a picture of him in front of the Eiffel Tower and then I showed her that as soon as she got home. So he also might send pictures to me for the girls to look at as a kind of form of communication." (Female (partner) - Family interview)

"We Skype, mainly in the house, I would call them. You can see what they are doing so they can show you things they've made or drawn or pictures or something, something they can show you, so take the iPad around the house and show you things." (Male (worker) Family interview)

While sharing experiences was generally seen as extremely positive, in contrast, there were examples in which ICT communication created less than ideal shared experiences. This was felt by the inability of technology to convey certain meanings (via text or phone call for example) leading to frustration and creating tensions that would not necessarily have arisen if the conversations had been conducted in a co-present context.

"I think the reality is when we converse normally face to face, I can tell him to shut up or... or just walk off if it's getting boring - and [mobile worker] can do the same. Obviously you can't do that on the phone, so all of those body language things don't work." (Female (partner) - Family interview)

Negative aspects were also related to interruptions, either on the part of the family disturbing the employees' work-time, or employees disrupting meal times or bed times at home, particularly for 
those with young children. Tensions surrounding sharing experiences were also evident due to the different roles of travelling away or being at home, as illustrated by the quotes below.

"I think it's easier for the person who goes away, because all you do is go away.....whereas the person who gets left behind gets left with everything, and they've got to carry on doing their job as well... (Female mobile worker)

"I like the feeling of liberation, this is going to sound terrible......" (Female mobile worker)

The shouldering of domestic responsibilities to others and the feeling that travel did provide a break from home routines did manifest itself as a sense of guilt for a number of respondents.

Participants also discussed their thoughts on future technologies and what might improve communication. To a large extent, these revolved around more expressive technologies, devices to help bridge the physical distance, as explained in the following quote;

"I feel very close to her (daughter) and I want more than I can get through the mediums I've got" (female, consultant).

This desire for more expressive technologies that can replicate physical closeness in some way appeared to be an expression of what the traveller missed when away from home.

In terms of the value of ICT-enabled communication, the overwhelming consensus was the ability to be present when absent. ICTs provide the means to extend the work home interface that fosters a sense of work-life balance. 'Being away' is no longer just about work, but allows for continued involvement with family. Virtual presence enables a form of connection to home, thereby blurring the boundaries between home and away, between work and life, time and space. We conclude that for our employees and their families the practice of connecting to home serves a number of different functions. Cumulatively these have a role to play in maintaining some sense of a work-life balance when working on-the-move. For employees, the use of ICTs for border crossing extends beyond bridging locations within a work role to border permutation between work and family roles.

\section{Conclusions}

This paper sought to explore the role that ICTs have in enabling connections to home for people whose work necessitates some element of mobility. Specifically we wanted to understand the 
potential for ICTs to foster a sense of work-life balance for mobile employees. For organisations, ICTs primarily provide the means for connecting to and carrying out work related activities. Those who travel for work are not currently seen by ??? as having specific challenges in relation to work-life balance. For employees, ICTs are routinely used for work when travelling, however they are also a valuable means to connect to home. Given that both employers and employees express an interest in a healthy work-life balance, we now reflect on these work/home relationships for improving work-life balance for employees and their families.

To suggest that organisations should provide support for maintaining a balance between work and home demands is not new (Striker et al, 1999). There is no doubt that for organisations, the work-life balance of employees is an important concern with policies surrounding flexible working and family friendly structures evident. These go some way in facilitating work-life balance opportunities. In additional to formal policies, work-life balance issues are often viewed as an HR issue to be negotiated individually by employees (Todd and Binns, 2013). Our findings support this. In our study, those whose work frequently takes them away from home were not considered as a separate group who may have specific needs distinct from nontravelling colleagues, despite ample evidence that work related travel presents significant strains. If absence from home has a negative impact on achieving work-life balance, employers have not yet considered the potential implications, neither have they considered how ICTs might be usefully employed to mediate negative perceptions. Our research points towards a missed opportunity on the part of employers in terms of implementing structures or policies that could underpin and support ICT use for home connections.

Given that business travel appears an increasing feature of the modern workforce, maintaining the health of their mobile workforce creates challenges for employers. There is a need for human resource practitioners to be aware of the effects of business travel on family life and work-life balance. In so doing, they may be able to ensure access to adequate and appropriate technologies that enable expressive communication with home to ease the impacts of absence. This might be in terms of provision of devices and clarity around the acceptable use of these technologies for personal use. Work based interventions that support challenges such as the disruption of routines; tiredness and stress associated with travelling could also be explored. Training for employees (and potentially their families) in dealing with periods of absence and return may also offer benefits.

ICTs clearly have a positive function in connecting to home. Regular communication is important for the psychological well-being of people who are away from their homes and loved ones (Greene et al., 2010). It can also be argued that staying in touch is more important than 
the content of the communication (Pink et al 2016). Technology affords new forms and patterns of personal communication; it is a new tool for connecting with its own set of clues and signals (Baymna 2010). Our research shows how technology that facilitates the most expressive forms of communication, enables the traveller to feel a sense of connectedness to family life. Whilst ICTs cannot yet act as a substitute for face-to-face interactions (Jones, 2013), at the same time it is apparent that it can enable a sense of connectedness for business travellers and their families. Our findings offer some evidence that expressive forms of communication which enable visual encounters for both the traveller and those left at home do provide some comfort and reassurances when 'checking-in' and more importantly for 'maintaining relationships' and 'sharing experiences' whilst on the move. The value of this for how individuals view their worklife balance is evident. Novel and innovative technologies may be able to facilitate more meaningful communication, and this would provide a fruitful line of enquiry for future research.

Our research adds to conversations on boundary management as technology removes spatial boundaries, enabling virtual presence and extending the opportunity for family interaction. ICTs challenge the importance of proximity and co-location in the maintenance of relationships (Pink et al 2016). Our interviews with employers reveal awareness of a distinction between work and home, and a desire to engage in practice that fosters a sense of 'balance' between the two. How this can be supported by ICTs in the context of those who work away from home continues to evolve. For those away from home, whilst there may be a physical detachment from workplace and family, ICTs enable boundary crossing and connections to be maintained. One consequence of boundary crossing is that business trips may impact on travellers, their families and organisations simultaneously. In terms of the travellers and their families, on the one hand boundary crossing allows for involvement in family life through a virtual presence that helps to facilitate a sense of work-life balance. However, there may also be negative consequences brought about by the ease of boundary crossing. One repercussion is there is no respite or detachment from the mundane or the responsibilities and daily demands of family life. In this way, ICTs challenge the business trip as a respite (Westman, Etzion and Gattenio; 2008; Westman, Etzion and Chen 2009) or a removal from family responsibilities (Bergström Casinowsky, 2013) as the traveller is available to fulfil at least some family related roles. Our research also points towards potential conflicts resulting in instances where the business traveller was seen to be 'having a good time' whereas the family are left with the challenges of coping without one family member. There is some evidence of guilt that others are left behind; therefore a compulsion to remain 'connected' helps to share the responsibilities. There were also times when communication was unclear or connecting happened at inconvenient times. Interruptions take the form of intrusions from one role into another (Kossek et al.,2012) and these were evident in our sample. These negative aspects point towards a potential need for 
boundary crossing from work to family spheres to be negotiated, thus mitigating negative effects whilst supporting positive ones.

Our research offers some reflection on what constitutes the essence of work-life balance. Practices of connecting to home were based around the three activities of checking in, maintaining relationships and sharing experiences. Recognising the criticism by Grzywacz and Carlson (2007) that treating work-life balance as a psychological construct ignores the contextual and social perspective of work-life balance, we argue that in the context of absence from family due to work, the practice of how and why people connect to home reflects what is important to them, and also the expectations of both those who are absent and their families. what is valued and expected. Supporting the notion that balance is the "accomplishment of role related expectations that are negotiated and shared between an individual and his or her rolerelated partners in the work and family domains" (Grzywacz and Carlson, 2007 p 458) the shared actions between travellers and their families fosters some sense of work-life balance, whatever these may be. Finding this 'balance' may partly be due to the extent of consensus around these activities and how and where boundaries are drawn or crossed.

Our research has a number of limitations. First, the work is exploratory with a small sample size and we canot generalise from our findings. Second, previous evidence suggests that business travel is a highly gendered activity (Bergström-Casonowsky, 2012; 2013). Our sample reflects the male dominated business travel sector, and our line of questioning did not consider how work related travel and responsibilities towards home may differ according to gender. ICTs which enable boundary crossing clearly have an infuence in terms of respite (or not) from home related responsibilities. Our research also did not consider travel frequency or location of travel - therefore differences between those for whom travel is extensive (as in Bauman's (2000) hypermobile elites) or international and domestic travel could not be ascertained. Both of these aspects potentially affect practice regarding connecting to home, and are worthwhile areas for further research.

We began our paper by stating that work-related travel has become commonplace and that ICTs are reshaping the experience of work mobility and absence for both travellers and their family who remain at home. The full implications of such work related travel and absence on the traveller and their families may well be better understood over time, therefore we support Westman et al's (2009) call for longitudinal studies. Studies that examine these relationships across the life span would be a valuable way to understand these implications. Multidisciplinary dialogue between social science, business, human resources management, human computer interaction and ICT researchers may be better able to explore and understand 
complex human technology relationships, mobile working practices and the significance of family connections whilst away from home. Reflecting on the central theme of our paper, to ascertain how individual's transition between work and family life through technology in an effort to achieve work-life balance, we have offered some insights into the practices of boundary crossing between home and work and how ICT's facilitate that practice. We have also shown the potential for business travel and work-life balance research to jointly consider the influences and further potential of ICTs. 


\section{References}

Aguilera, A. (2008) Business travel and mobile workers. Transportation Research Part A 42, 42, 1109-1116.

Aguiléra, A. \& Proulhac, L. (2015) Socio-occupational and geographical determinants of the frequency of long-distance business travel in France. Journal of Transport Geography 43, 28-35.

Allen, T.D., Cho, E., and Meier, L.L. (2014). Work-family boundary dynamics. The Annual Review of OrganisationalPsychology andOrganizational Behaviour. 1:99-121.

Bauman, Z. (2000) Liquid Modernity, Cambridge, Polity Press.

Baymna, N. (2010). Personnal Connections in the Digital Age: Cambridge: Polity.

Beauregard, T. A. \& Henry, L. C. (2009) Making the link between work-life balance practices and organizational performance. Human Resource Management Review 19, 9-22.

Bergström-Casonowsky, G. (2013). Working life on the move, domestic life at a standstill? Work related travel and responsibility for home and family. Gender, Work and Organization 20(3): 311-326.

Bergström-Casonowsky, G. (2010) Consequences of Overnight Work Travel for Personal Social Relations: Problems, Promises, and Further Repercussions Mobilities, 5, 369-386.

Black, I., and Jamieson, S. (2007). Up, up and fading away: the work and family life of executvie business travellers. Policy and Practice in Health and Safety 5: 63-78.

Campbell Clark. S. (2000). Work'family border theory: A new theory of work/family balance. Human Relations 53(6): 747-770.

Carlson, D.S., Grzywacz, J.G. and Zivnuska, S. (2009). Is work-family balance more than conflict and enrichment? Human Relations 62, 10, 1469-1486.

Casper, W. J. \& Buffardi, L. C. (2004) Work-life benefits and job pursuit intentions: The role of anticipated organizational support. Journal of Vocational Behavior 65, p391-410.

Charmaz, K. (2006). Constructing Grounded Thory: A Practical Guide through Qualitative Analysis. Thousand Oaks CA, Sage.

DeFrank, R. S., Konopaske, R. \& Ivancevich, J. M. (2000) Executive travel stress: Perils of the road warrior. Academy of Management Executive, 14, 58-71.

Dewe, P. \& Kompier, M. (2008) Wellbeing and Work: Future Challenges. Foresight. Mental Capital and Wellbeing Project.London, UK: The Government Office for Science.

Espino, C. M., Sundstrom, S. M., Frick, H. L., Jacobs, M. \& Peters, M. (2002) International business travel: impact on families and travellers. Occup Environ Med 59, 309-322.

Faulconbridge, J. R., Beaverstock, J. V., Derudder, B. \& Witlox, F. (2009) Corporate Ecologies of Business Travel in Professional Service Firms. Working Towards a Research Agenda. European Urban and Regional Studies 16, 295-308.

Fleetwood, S. (2007) Why Work-Life Balance Now? . The International Journal of Human Resource Management 18, 387-400.

Gold, M., and Mustafa, M. (2013). 'Work always wins': client colonisaton, time management and the anxieties of connected freelancers. New Technology, Work and Employment 28, 3, 197-211.

Greene, T., Buckman, J., Dandeker, C. \& Greenberg, N. (2010) How communication with families can both help and hinder service members' mental health and occupational effectiveness on deployment. Military Medicine 175, 745-749.

Grzwacz, J.G., and Carlson, D. S. (2007). Concepturalising work-family balance: Implications for practice and research. Advances in Developing Human Resources 9, 4, 455-471.

Gustafson, P. (2006) Work-related travel, gender and family obligations. Work, Employment and Society 20, 513-530. 
Gustafson, P. (2012) Managing business travel: Developments and dilemmas in corporate travel management. Tourism Management 33, 276-284.

Gustafson, P. (2014) Business Travel from the Traveller's Persective: Stress, Stimulation and Normalization. Mobilities 9, 63-83.

Haynes, P. (2010) Information and Communication Technology and International Business Travel: Mobility Allies? Mobilities 5, 547-564.

Hilbrecht, M., Shaw, S.M., Johnson, L.C., and Andrey, J. (2013). Remising work, family and leisure: teleworkers' expereinces of everyday life. New Technology, Work and Employment 28, 2, 130-144.

Holley, D., Jain, J. \& Lyons, G. (2008) Understanding business travel time use and its place in the working day. Time \& Society 17, 27-46.

Horst, H. (2013). The infrastructures of mobile media: Towards a future research agenda. Mobile Media and Communication 1(1): 147-152.

Ivancevich, J. M., Konopaske, R. \& DeFrank, R. S. (2003) Business travel stress: a model, propositions and managerial implications. Work and Stress, 17, 138-157.

James, A. (2011). Work-life(im) 'balance' and its consequences for everyday learning and innovation in the New Economy: evidence from the Isish IT sector. Gender, Place and Culture 18, 5, 655-684.

Jamieson, L. \& Morton, S. (2005) Work-Life Balance Across the Lifecourse. Research Briefing 21, Centre for Research on Families and Relationships, University of Edinburgh.

Jennings, G., Kensbock, S., Junek, O., Radel, K. \& Kachel, U. (2010) Lived experiences of early career researchers: learning about and doing grounded theory. Journal of Hospitality and Tourism Management 17, 21-33.

Jensen, M. T. (2014) Exploring business travel with work-family conflict and the emotional exhaustion component of burnout as outcome variables: The job demands-resources perspective. European Journal of Work and Organizational Psychology 23, 497-510.

Jones, A. (2013) Conceptualising business mobilities: Towards an analytical framework. Research in Transportation Business \& Management 9, 58-66.

Jones, F., Burke, R.J., amd Westman, M. (2006). Work-life balance: a psychological perspective. Psychological Press. New York, NJ.

Kaufman-Scarborough, C. (2006). Time use and the impact of technology: Examining workspaces in the home. Time and Society 15, 1, 57-80.

Kellerman, A. (2010) Business travel and leisure tourism: Comparative trends in a globalizing world. In Beaverstock, J.V., Derudder, B., Faulconbridge, J. \& Witlox, F. (Eds.) International business travel in the global economy. Farnham, Ashgate.

Koroma, J., Hyrkkänen, U., and Vartiainen, M. (2014). Looking for people, places and connections: hindrances when working in multiple locations: a review. New Technology, Work and Employment 29, 2, 139-159.

Kossek, E.E., Ruderman, M.N., Braddy, P.W., and Hannum, K.K. (2012). Work-nonwork boundary management profiles: A person-centered appraoch. Journal of Vocational Behaviour. 81: 112-128.

Larsen, J., Axhausen, K. W. \& Urry, J. (2006) Geographies of Social Networks: Meetings, Travel and Communications. Mobilities 1, p261-283.

Larsen, J., Urry, J. \& Axhausen, K. (2008) Coordinating Face-to-Face meetings in mobile network societies Information, Communication \& Society 11, 640-658.

Lee, S. J. \& McCool, A. C. (2006) Business travelers' diet practices. Journal of Foodservice Business Research, 8, 3-19. 
Mäkelä, L., Bergbom, B., Tanskanen, J. \& Kinnunen, U. (2014) The relationship between international business travel and sleep problems via work-family conflict. Career Development International, 19, 794-812.

McDowell, L. (2007). Spaces of the home: absence, presence, new connections an new anxieties. Home Cultures 4, 2, 129-146.

McDowall, A. \& Nicolas, H. (2012) When work keeps us apart: a thematic analysis of the experience of business travellers. Community, Work and Family 15, 335-355.

Madianou, M., and Miller, D. (2011). Mobile phone parenting: Reconfiguring relationships between Filipina migrant mothers and their left-behind children. New Media and Society 13, 3, 457-470.

Morgan, D. (2011). Rethinking Family Practices. Basingstoke, Palgrave Mcmillan.

Nansen, B., Arnold, M., Gibbs, M., and Davis, H. (2010). Time, space and technology in the working-home: an unsettled nexus. New Technology, Work and Employent 25, 2, 136153.

Neuhofer, B., Buhalis, D., and Ladkin, A. (2013). Concepturlaising technology enhanced destination espereinces. Journal of Destination Marketing and Management 1, 1, 36-46.

Numes, F. (2005). Most relevent enablers and constraints influencing the spead of telework in Potugal. New Technology, Work and Employment 20, 2, 133-149.

ONS (2015) Travel Trends, 2014. Office for National Statistics.

Perry, M., O'Hara, K., Sellen, A., Brown, B. \& Harper, R. (2001) Dealing with Mobility: Understanding access anytime, anywhere. ACM Transactions on Computer-Human Interaction 8, 323-347.

Peters, P., Den Dulk, L. \& van der Lippe, T. (2009) The effects of time-spatial flexibility and new working conditions on empoyee's work-life balance: the Dutch case Community, Work \& Family 12, 279-297.

Pink, S., Horst, H., Postill, J., Hjorth, L., Lewis, T., and Tacchi, J. (2016). Digital Ethnograohy: Principles and Practice. Sage. London.

Rogers, H. L. \& Reilly, S. M. (2002) A survey of the health experiences of international business travelers. Part One--Physiological aspects. AAOHN journal : official journal of the American Association of Occupational Health Nurses, 50, 449-459.

Sayah, S. (2013). Managing work-life boundaries with incofmration and communication technologies: the case of inependent contractors. New Technology, Work and Employment 28, 3, 179-196.

Small, Harris, Wilson \& Ateljevic (2011) Voices of women: A memory-work reflection on worklife dis/harmony in tourism academia Journal of Hospitality, Leisure, Sport and Tourism Education 10, 23-36.

Storme, T., Beaverstock, J. V., Derrudder, B., Faulconbridge, J. R. \& Witlox, F. (2013) How to cope with mobility expectations in academia: Individual travel strategies of tenured academics at Ghent University, Flanders. Research in Transportation Business \& Management 9, 12-20.

Striker, J., Luippold, R.S., Nagy, L., Liese, B., Bigelow, C., and Mundt, K.A. (1999). Risk factors for psychological stress among international business travellers. Occupational and Environmental Medicine 56: 245-252.

Tang, L. (2012). Waiting together: Seafarer-partners in cyberspace. Time and Society 21, 2, 223-240.

Ter Hoeven, C.L., and Van Zoonen, W. (2015). Flexible work designs and employee well-being: examining the effects of resources and demands. New Technology, Work and Employment 30, 3, 237-255).

Todd, P., and Binns, J. (2013). Work-life balance: Is it now a problem for management? Gender, Work and Organization 20(3): 219-231. 
Tompkins, O. S. (2008) Business traveler fitness. AAOHN journal : official journal of the American Association of Occupational Health Nurses, 56, 272.

UNWTO (2014) Global Report on the Meetings Industry. AM Reports, Volume 7. Madrid, UNWTO.

UNWTO (2015) Tourism Highlights 2015 Edition. Madrid, Spain.

Wajcman, J., Bittman, M. \& Brown, J. E. (2008) Families without Borders: Mobile Phones, Connectedness and Work-Home Divisions. Sociology 42, 635-652.

Westman, M., Etzion, D. and Gattenio,E. (2008). International business traveks and the work family inteface: A longitudinal study. Journal of Occupational and Organizational Psychology. 81: 459-480.

Westman, M., Etzion, D., and Chen, S. (2009). Are business trips a unique kind of respite? In Current Perspectives on Job-Stress Recovery. Edited by Sonnetag, S., Ganster, D.C., and P.L. Perrewe,. 167-204. Bingley: Emerald.

Westman, M. \& Etzion, D. (2002) The impact of short overseas business trips on job stress and burnout. Applied Psychology: An International Review 51, 582-592.

White, N.R., and White, P.B. (2007). Home and away: Tourists in a connected world. Annals of Tourism Research 34, 88-104..

Yeow, J. (2014). Boundary management in n ICT-enabled project-based organissing context. New Technology, Work and Employment 29, 3, 237-252. 
Table 1: Employer and Employee Sample Profile

\begin{tabular}{|c|c|c|}
\hline \multicolumn{3}{|l|}{ Employers } \\
\hline Industry & Type of organisation & No. interviewed \\
\hline \multirow[t]{3}{*}{ Tourism and Hospitality } & Hotel & 3 \\
\hline & Cruise operator & 2 \\
\hline & Tour operator & 1 \\
\hline \multirow[t]{3}{*}{ Transport } & Airline & 1 \\
\hline & Logistics/haulage & 2 \\
\hline & Transport research/advocacy & 2 \\
\hline Media & TV channel & 1 \\
\hline \multirow[t]{3}{*}{ Other } & Consultancy & 1 \\
\hline & Pharmaceuticals & 1 \\
\hline & Development charity & 1 \\
\hline \multicolumn{3}{|l|}{ Employees } \\
\hline \multirow[t]{2}{*}{ Gender } & Male & 13 \\
\hline & Female & 6 \\
\hline \multirow[t]{5}{*}{ Work travel frequency } & Up to 20 nights per year & 5 \\
\hline & Up to 50 nights per year & 1 \\
\hline & Up to 100 night per year & 3 \\
\hline & $\begin{array}{l}\text { More than } 100 \text { nights per } \\
\text { year }\end{array}$ & 6 \\
\hline & 'Frequent' (no. not specified) & 4 \\
\hline \multirow[t]{7}{*}{ Occupation } & Consultant & 5 \\
\hline & NGO & 4 \\
\hline & Academic & 2 \\
\hline & Journalism/Publishing & 2 \\
\hline & Training/technical advisor & 2 \\
\hline & Sales & 1 \\
\hline & Other & 3 \\
\hline
\end{tabular}

